\title{
Impact of Herbal Supplement on CD4 Cell Count among Institutionalized HIV-AIDS Subjects in Puducherry
}

\author{
S. Kamashi ${ }^{*}$ and Raji V. Sugumar ${ }^{2}$ \\ 'Research Scholar, Department of Food Science and Technology, Pondicherry University, \\ Puducherry-605014, India; kamashi88@gmail.com \\ ${ }^{2}$ Associate Professor \& Head, Department of Home Science, Avvaiyar Govt. College for Women, \\ Karaikal, UT of Puducherry - 609602, India; rajis207@gmail.com
}

\begin{abstract}
Acquired Immuno Deficiency Syndrome is a fatal illness caused by Human Immuno-deficiency Virus, which breaks down the host immune system, leaving the subject vulnerable to life-threatening infections. Current therapies available for symptomatic treatment of AIDS are quite expensive and are seeking help from alternative system of medicines. Findings suggest beneficial effects from herbs but require more evidences. Hence, this is a step to popularize indigenous herbs which possess immuno- modulatory properties against retrovirus; inhibits the replication of it in human body, also prevent infectious diseases and hence delays the progression of the disease. Thus this study was ventured upon at a pilot level to formulate a multi herbal product and to study its impact on supplementation to HIV-AIDS subjects. The herbal product comprises of four different herbs namely Achyranthes aspera (600mg), Tribulus terrestris (300mg), Trichopus seylanicus (400 $\mathrm{mg}$ ),Tinospora cordifolia $(200 \mathrm{mg})$ and rice bran $(500 \mathrm{mg})$ in different dosage. The ingredients were shade dried and powdered and 2 grams of the mix with the above mentioned proportion was administered to the subjects twice a day to be consumed along with cooked hot rice. The impact of the developed multi herbal supplement was studied before and after the treatment with reference to CD4 count. The finding of the study revealed that about $75 \%$ of the subjects showed improvement in the CD4 count on supplementation. The present study concluded that these potential herbs could be supplemented to the HIV-AIDS patients along with the ART drugs to boost their immune system.
\end{abstract}

Keywords: Anti-Retroviral Therapy, CD4, HIV-AIDS, Immune-Modulator Property

\section{Introduction}

India has the third largest number of people living with HIV/AIDS (Human Immuno-deficiency Virus / Acquired Immuno Deficiency Syndrome). In 2008-09, there were 23.9 lakh people affected by HIV/AIDS in India. Once infected, it is probable that a person will be infected for life. The progression of HIV leads to AIDS and many opportunistic Infections which results in death due to both the replication of the Retrovirus ( $>400$ copies $/ \mathrm{ml}$ ) and the depletion of the immune cells especially CD-4 cells $(<350 /$ cubic mm). Current therapies available for sympto- matic treatment of AIDS are quite expensive beyond the reach of common man and are associated with emergence of drug resistance. Many patients with AIDS are seeking help from alternative systems of medicines such as Unani, Ayurvedic, Naturopathy, and Homeopathy. Since a long time, medicinal plants have been used for the treatment of many infectious diseases without any scientific evidence. At present there is more emphasis on determining the scientific evidence and rationalization of the use of these preparations. Research is in progress to identify plants and their active principles possessing activity against sexually transmitted pathogens including HIV with an objective of

${ }^{*}$ Author for correspondence 
providing an effective approach for prevention of transmission and treatment of these diseases. Many such findings suggest beneficial effects from some of the tested herbs but more evidence from larger studies are needed. This study is a step to reach the unreached with the indigenous herbs which possess immuno modulatory properties against retrovirus and inhibit the replication of it in human body and also prevent infectious diseases and hence delays the progression of the disease [1]. Certain herbs possess immune modulatory properties which could contribute significant changes in HIV-AIDS patient's immune system. Tribulus terristrisis a nutritive agent with $10-15$ percent protein. It is a diuretic and improves the glomerular filtration rate. It inhibits the angiotensin converting enzyme and thus has hypertensive action.

It is also used in folk medicine as tonic, aphrodisiac, analgesic, astringent, stomachic, anti-hypertensive, lithon-triptic and urinary anti-infectives [2]. Acharanthes aspera contain alkaloids and tannins showed hepatoprotective activity [3]. Trichopus zeylanicus possess NADH, polyphenols and sulfhydryl compounds which have important mechanism in antioxidant activity also contain anti-fatigue properties [4]. An arabinoxylane from rice bran contains potent anti-HIV activity which is useful for treating patients with AIDS [5].

\section{Materials and Methods}

The herbs selected for the study were Tribulus terristris (Nerunjil Mul), Tinospora cardifolia (Seenthil Sarkarai), Acharanthes aspera (Nayuurvi) and Trichopus zeylanicus (Arokiya Pachillai). Rice bran was added to improve the fiber content of the supplement. All the herbs were procured in bulk quantity, cleaned, washed, shade dried, powdered and stored in glass jars which ensures the uniformity in the ingredients throughout the product. The selected herbs were formulated in a specific proportion based on their intensity of medicinal properties against HIV-AIDS. The proportion of the formulated herbal mixture was Acharnthes aspera - 600mg, Tribulus terristris -300mg, Trichopus zeylanicus - 400mg, Tinospora cardifolia - 200mg and rice bran - 500mg. The developed product was analysed for its nutrient content and sensory attributes and administered to the subjects. Technical cooperation of medical botanists was sought. Organoleptic evaluation was carried out by the 30 semi-trained panel members from the college. They examine the developed herbal mixture for its color, flavor, texture, palatability and appearance. All the ingredients were measured and packed in a Low Density Polypropylene (LDP) packet each packet weighing $2 \mathrm{gm}$.

The HIV subjects for the supplementation were selected from an AIDS rehabilitation center in Puducherry. Informed consent were obtained from the institution and the individual subjects. The intervention was done for a period of 90 days. Each subject was supplemented with $2 \mathrm{gm}$ of herbal mixture twice a day during lunch and dinner by mixing it in hot rice with ghee.

\section{Results and Discussion}

\subsection{Analysis of Nutrients in the Developed Herbal Product}

The developed mixture was analysed for its proximate principles, micro nutrients and other essential elements by adopting AOAC procedures (Table 1).

Supplemented herbal product contain $3.72 \%$ of Ash; $12.52 \%$ of Moisture; $11.47 \%$ of Protein; $65.66 \%$ of Carbohydrate; $5.99 \%$ of Fat; 368 K.calories per 100 g; Vitamin - A - $15.66 \mathrm{mcg} / \mathrm{g}$; Vitamin - C - $1.93 \mathrm{mg} / \mathrm{g}$; Vitamin B1- $0.11 \mathrm{mg} / \mathrm{g}$; Vitamin B6 - 0.26mg/g; Vitamin B2 - 0.02mg/g; Zinc - 5.4mg/g; Calcium - $23.3 \mathrm{mg} / \mathrm{g}$; Selenium $-0.11 \mathrm{mcg} / \mathrm{g}$; Folic acid $-0.37 \mathrm{mcg} / \mathrm{g}$; Niacinamide

Table 1. Nutrient profile of developed herbal product

\begin{tabular}{|l|c|}
\hline Elements & Quantity \\
\hline Ash (\%) & 3.72 \\
\hline Moisture (\%) & 12.52 \\
\hline Protein (\%) & 11.47 \\
\hline Carbohydrate (\%) & 65.66 \\
\hline Fat (\%) & 5.99 \\
\hline Energy (K.Cal) & $368 / 100 \mathrm{~g}$ \\
\hline Vitamin A (mcg) & $15.66 / \mathrm{g}$ \\
\hline Vitamin C (mg) & $1.93 / \mathrm{g}$ \\
\hline Vitamin B1 (mg) & $0.11 / \mathrm{g}$ \\
\hline Vitamin B6 (mg) & $0.26 / \mathrm{g}$ \\
\hline Vitamin B2 (mg) & $0.02 / \mathrm{g}$ \\
\hline Zinc (mg) & $5.45 / \mathrm{g}$ \\
\hline Iron (mg) & $1.45 / \mathrm{g}$ \\
\hline Calcium (mg) & $23.3 / \mathrm{g}$ \\
\hline Selenium (mcg) & $0.11 / \mathrm{g}$ \\
\hline Folic acid (mcg) & $0.37 / \mathrm{g}$ \\
\hline Niacinamide (mg) & $2.15 / \mathrm{g}$ \\
\hline
\end{tabular}


$-2.15 \mathrm{mg} / \mathrm{g}$. Ash content represents the inorganic residues remained after the application of heat in foods. The total amount of minerals in food was estimated by determining the ash content [6]. The herbal mixture supplemented in the present study undergone minimal processing viz. cleaning, washing and shade drying which could significantly attributed to the maximum retention of the nutrients and bioactive compounds naturally present in the selected herbs. Water soluble and heat labile vitamins such as vitamin B1, B2, B6, Niacinamide and vitamin A and vitamin $\mathrm{C}$ were preserved within the leaf granules due to non-thermal processing technology.

The most essential micronutrients were compared with RDA and is represented in Table 2.

The amount of micronutrients present per gram of the herbal mixture was calculated for $4 \mathrm{~g}$ as the supplementation contains $2 \mathrm{~g}$ of mixture twice a day for 90 days. The micronutrients derived from the herbal mixture is compared with the RDA for men and women. Fromt the study it is revealed that the formulated and supplemented herbal mixture contain $7.72 \mathrm{mg}$ of vitamin $\mathrm{C}$ which met $19 \%$ of RDA for both men and women; 0.44mgof vitamin B1 which met $36 \%$ and $44 \%$ of RDA for men and women respectively; $1.04 \mathrm{mg}$ off vitamin $\mathrm{B} 6$ which met $52 \%$ of RDA for both the gender; $0.08 \mathrm{mg}$ of vitamin $\mathrm{B} 2$ which met $5.7 \%$ and $7.2 \%$ of RDA for men and women respectively; $21.8 \mathrm{mg}$ of zinc and $5.8 \mathrm{mg}$ of iron which met more than the RDA's requirementfor men and women; $93.2 \mathrm{mg}$ of calcium which met $15.5 \%$ of RDA for men and women; $8.6 \mathrm{mg}$ of niacinamide which met $53 \%$ and $71 \%$ of RDA for men and women. The same is better illustrated in Figure 1.

Table 2. Comparison of micronutrients in the developed herbal mixture with RDA

\begin{tabular}{|l|c|c|c|c|}
\hline \multirow{2}{*}{ S.No } & \multirow{2}{*}{ Micronutrients } & Developed & \multicolumn{2}{|c|}{ RDA/Day } \\
\cline { 4 - 5 } & & Product (4g) & Men & Women \\
\hline 1. & Vitamin C & $7.72 \mathrm{mg}$ & $19 \%$ & $19 \%$ \\
\hline 2. & Vitamin B1 & $0.44 \mathrm{mg}$ & $36 \%$ & $44 \%$ \\
\hline 3. & Vitamin B6 & $1.04 \mathrm{mg}$ & $52 \%$ & $52 \%$ \\
\hline 4. & Vitamin B2 & $0.08 \mathrm{mg}$ & $5.7 \%$ & $7.2 \%$ \\
\hline 5. & Zinc & $21.8 \mathrm{mg}$ & $>100 \%$ & $>100 \%$ \\
\hline 6. & Iron & $5.8 \mathrm{mg}$ & $>100 \%$ & $>100 \%$ \\
\hline 7. & Calcium & $93.2 \mathrm{mg}$ & $15.5 \%$ & $15.5 \%$ \\
\hline 8. & Niacinamide & $8.6 \mathrm{mg}$ & $53 \%$ & $71 \%$ \\
\hline
\end{tabular}

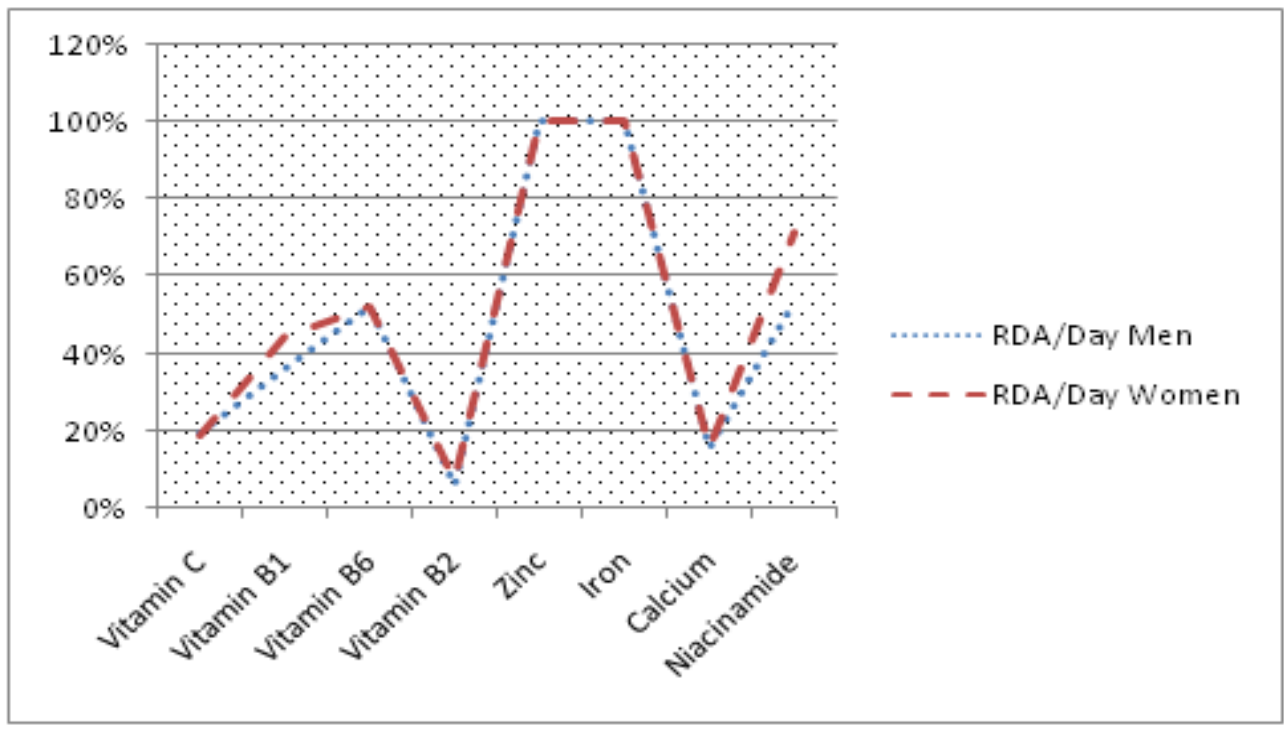

Figure 1. Comparison of Micronutrients in the Herbal Product with RDA. 
The sensory attributes of the developed product such as color, flavor, texture, palatability and appearance were evaluated by three point scale and is given in Table 3 .

From the organoleptic evaluation it is obvious that $60 \%, 30 \%$ and $10 \%$ of the respondents opined that the appearance of the herbal product was good, fair and poor respectively; $75 \%, 20 \%$ and $5 \%$ of the respondents felt that the color of the product was good, fair and poor respectively.; as far as flavor was concerned 85 percent of the respondents evaluated as good, 15 percent as fair and 5 percent as poor; 65 percent of the respondents were evaluated the texture as good, 20 percent as fair and 15 percent as poor; to mention about the palatability of the product 35 percent of the respondents opined as good, 40 percent as fair and 25 percent as poor. From the above Table 3 it is evident that out of 5 attributes 4 secured higher percentage. Higher scores $(75 \%)$ with respect to color might be due to the retention of nutrients without

Table 3. Organoleptic evaluation of the herbal supplementation

\begin{tabular}{|l|c|c|c|c|}
\hline Sl.No & Attributes & Good (\%) & Fair (\%) & Poor (\%) \\
\hline 1. & Appearance & 60 & 30 & 10 \\
\hline 2. & Colour & 75 & 20 & 5 \\
\hline 3. & Flavour & 85 & 10 & 5 \\
\hline 4. & Texture & 65 & 20 & 15 \\
\hline 5. & Palatability & 35 & 40 & 25 \\
\hline
\end{tabular}

Table 4. Impact of herbal supplementation on CD4 count

\begin{tabular}{|c|c|c|c|}
\hline Respondents & $\begin{array}{c}\mathrm{A} \\
(\text { Impact of ART) } \\
\mathrm{T} 1\end{array}$ & $\begin{array}{c}\text { B } \\
\text { (Impact of ART }+ \\
\text { Supplementation) } \mathrm{T} 2\end{array}$ & $\begin{array}{c}\text { C } \\
\text { (Impact of } \\
\text { Supplementation) T3 }\end{array}$ \\
\hline 1 & 213 & 297 & 312 \\
\hline 2 & 221 & 280 & 300 \\
\hline 3 & 212 & 250 & 280 \\
\hline 4 & 229 & 272 & 250 \\
\hline 5 & 220 & 250 & 280 \\
\hline 6 & 365 & 490 & - \\
\hline 7 & 223 & 420 & - \\
\hline 8 & 778 & 654 & - \\
\hline 9 & 378 & 419 & - \\
\hline 10 & 721 & 593 & - \\
\hline 11 & 505 & 683 & - \\
\hline 12 & 159 & 170 & - \\
\hline 13 & 312 & 593 & 550 \\
\hline 14 & 83 & 188 & 250 \\
\hline 15 & 303 & 339 & 544 \\
\hline 16 & 181 & 214 & 344 \\
\hline 17 & 159 & 168 & 241 \\
\hline 18 & 105 & 365 & 344 \\
\hline 19 & 400 & 112 & 254 \\
\hline 20 & 211 & 246 & 312 \\
\hline Mean & 300 & 350 & 328 \\
\hline
\end{tabular}

A- Pre-CD4 cell count level with respect to ART alone; B- Post-CD4 count with respect to ART and the herbal Supplementation; C- CD4 count of the impact of the herbal supplementation alone. 


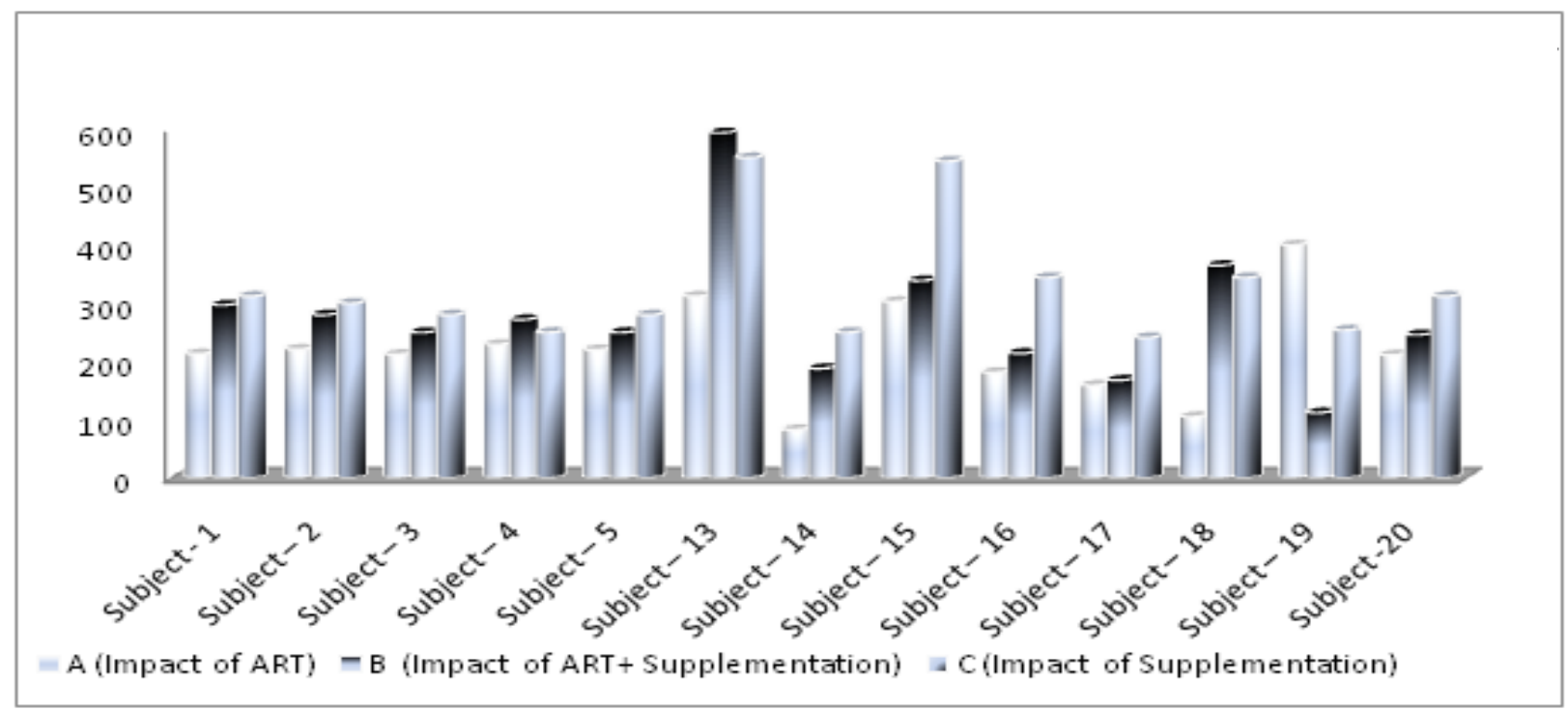

Figure 2. Impact of herbal supplementation on CD4 count.

much degradation of pigments as drying was carried out at low temperature. The palatability of the developed herbal product was not desirable due to the inclusion of the rice bran. The coarse texture of the rice bran made poor palatability of the herbal product.

\subsection{Impact of Herbal Supplementation}

The impact of herbal supplementation was done with reference to the increase in CD4 count before and after supplementation. The Herbal Mixture product consisted of four different herbs which possess potential immuno - stimulatory effects. At the start of the supplementation there were 20 subjects and by the end of the supplementation on the $90^{\text {th }}$ day there were only 13 subjects. The calculations were done accordingly and depicted in Table 4 .

The impact of herbal supplementation with respect to their increase of CD4 count was derived by using the simpler version of Panel Data Model (PDM) which is shown in the above Table 4. where, A is the initial CD4 cell count level with respect to ART alone, $B$ is the $\mathrm{CD} 4$ count with respect to ART and the herbal supplementation, $C$ is the CD4 count of the impact of the herbal supplementation alone. Mundewadi [7] also found that Ayurvedic medicines to be highly effective as anti-viral and immunostimulant, and safe on long-term use. A nutritious diet, herbal baseline therapy, timely allopathic treatment of opportunistic infections and regular counselling support appears to be an ideal combination in the management of HIV - AIDS patients. The mean impact of ART on CD-4
Cell count was 300, the mean impact of ART+ supplementation on CD-4 count was 350 and the mean impact of supplementation on CD-4 count was 328 .

$$
\begin{aligned}
\mathrm{A}= & 213 \text { (Impact of ART alone })=\mathrm{T} 1 \\
\mathrm{~B}= & 297-213=84 \text { (Impact of ART }+ \text { supplementation) } \\
& =\mathrm{T} 2-\mathrm{T} 1 \\
\mathrm{C}= & \mathrm{T} 3-\mathrm{T} 2
\end{aligned}
$$

312-297 = 15 (Impact of Supplementation alone)

The above findings are illustrated in Figure 2

From the Table 4 and Figure 2 it is obvious that except 7 subjects all the rest showed improvement in CD-4 count which implies increase in immune cells that can reduce the burden of disease. For subjects those of whom were in stage 3 of infection the effect of supplementation was minimal. About 75 percent of the respondents shown increased count of CD4 cells in a period of 90 days.

\section{Conclusion}

The study clearly confirms that administration of herbal mixture in right proportion increases the CD4 count and thus it can be advocated for boosting immunity.

\section{References}

1. National AIDS Control Organisation (NACO) Annual Report, Ministry of Health \& Family Welfare, Government of India, 2011. Available: http://www.naco.gov.in/NACO/ Quick_Links/Publication/Annual_Report/NACO_ Annual_Report/ 
2. Pallavigupta, A. K., and Kamal J., "Natural Immunomodulators as an Anti HIV Agent", Research on Environmental Life Science, vol. 2(2), p. 61-66, 2009.

3. Bafna A. R., and Mishra S. H., "Effect of methanol extract of Achyranthes aspera linn. on rifampicin-induced hepatotoxicity in rats", ArsPharmaceutica, vol. 45(4), p. 343-351, 2004.

4. Binu T., Murali K. D., Brown-Borg H. M., and Bala V. M., "Trichopuszeylanicus combats fatigue without amphetamine-mimetic activity", Phytotherapy Research, vol. 20(3), p. $165-168,2006$.
5. Mamdooh G., "Anti-HIV Activityin Vitroof MGN-3, an Activated Arabinoxylane from Rice Bran", Biochemical and Biophysical Research Communications, vol. 243(1), p. 25-29, 1998.

6. Monti., Nicola Di V., and Gianpietro V., "Mineral Composition and ash content of six major energy crops", Biomass and Bioenergy, vol. 32, p. 216-223, 2008.

7. Mundewadi A. A., Ayurvedic Management of HIV-AIDS, 2005. Available: http://www.articlecity.com/articles/ health/article_7030.shtml 